\title{
CORRESPONDENCE
}

Conservation: a small price for long-term economic well-being

SIR — Public funds should not just be channelled into boosting immediate economic recovery we must also be prepared to pay a higher 'insurance bill' to safeguard the ecological long-term basis of our economic and social wellbeing. Increased spending on conservation could help fund a worldwide core network of protected areas of biodiversity.

At the beginning of this year, worldwide economic stimulus plans totalled US $\$ 2.8$ trillion, with some $15.6 \%$ allocated to 'green' purposes such as climate protection (http://tinyurl.com/ ddrj69). In April, the G20 group of nations announced plans to spend US $\$ 5$ trillion by the end of 2010, to stimulate the floundering global economy and "accelerate the transition to a green economy". None of these funds is designated to the conservation of biological diversity - a fundamental resource for our economy and society.

The multilateral Global Environmental Facility (an independent financial organization uniting 178 member governments, in partnership with international institutions, non-governmental organizations and the private sector) has spent US $\$ 7.6$ billion on biodiversity conservation since 1991. In addition, we estimate that some $\$ 7.6$ billion has been contributed to this purpose each year by national governments.

We estimate that US $\$ 53$ billion is needed annually to maintain a global core network of protected areas (our update of figures from A. Balmford et al. Science 297, 950-953; 2002). This amount includes the income opportunities lost for the rural population of poor countries: mainly income that is, or could be, generated from tropical and subtropical agriculture.

It has been known for some time that the public in wealthy countries would be prepared to contribute additional funding to promote biodiversity conservation in the tropics (see, for example, B. Horton et al. Environ. Conserv. 30, 139-146; 2003). We believe that these contributions would today amount to US\$42-140 per household per year. Extrapolating this to each of about 452 million households of the member countries of the Organisation for Economic Co-operation and Development, we believe that roughly US $\$ 43$ billion could be generated annually. This sum would cover most of the global core network of sites earmarked for protection.

A dramatic increase in conservation spending is no fast fix for the economy. But conserving biological diversity contributes crucially to maintaining the resilience and adaptive capacity of the biosphere. In addition, it directly provides a multitude of critical ecological services (see, for example, http://tinyurl.com/ oee799).

Boris M. Hillmann, Jan Barkmann Georg-August-Universität Göttingen, Department of Agricultural Economics and Rural Development, Platz der Göttinger Sieben 5, 37073 Göttingen, Germany e-mail:bhillma@gwdg.de

\section{Conservation: the world's religions can help}

SIR - The world's religions are emerging as a surprising driver of support for conservation of biological diversity.

The International Interfaith Investment Group, for example, which is collectively worth more than US\$7 trillion, is encouraging religious organizations to change their current investment policies in favour of those that support conservation (www.3ignet.org).

In addition, lands owned by these organizations can contribute to the conservation of biodiversity because of their protected status. More than $7 \%$ of Earth's land surface is owned by religious institutions, and a further $8 \%$ has sacred links (www.arcworld.org). Given that most countries will never be able to designate more than $15 \%$ of their land as protected areas (S. Chape et al. Phil. Trans. R. Soc. B 360, 443-455; 2005), territory with religious and sacred affiliations contributes substantially to maintaining biodiversity.

It should also be possible to raise funding for conservation by appealing to donors who have religious faith. For example, the wealthy countries of the G20 group that have large religious populations might step in and help.

The focus of initiatives in the past has been on paying for ecosystem services, which are considered 'natural capital' (R. Costanza et al. Nature 387, 253-260; 1997), but an appeal to support native communities on religious grounds might prove more persuasive in a difficult economic climate.

Of the 125 countries that are represented in the Conservation International list of biodiversity hotspots (www. biodiversityhotspots.org), most have a low per-capita gross domestic product (GDP) and a strong religious base (http:// tinyurl.com/2b2kg9). Collectively, these countries are home to more than 4 billion people affiliated with one of 11 mainstream faiths; more than half of them have a total population of 3 billion and a per-capita GDP of less than US\$5,000.

Religious sympathy has the potential to make a major contribution towards biodiversity conservation. This contribution could be extremely valuable in the approach to the 2010 target of the Convention on Biological Diversity. Shonil Bhagwat School of Geography and the Environment, University of Oxford, South Parks Road, Oxford OX13QY, UK e-mail: shonil.bhagwat@ouce.ox.ac.uk Martin Palmer Alliance of Religions and Conservation, The House, Kelston Park, Bath BA1 9AE, UK

\section{Defining numbers in terms of their divisors}

SIR - In her informative Book Review of Yoko Ogawa's The Housekeeper and the Professor (Nature 460, 461-462; 2009), Jennifer Rohn nicely illustrates how one false premise will lead to all kinds of misunderstanding. She states that primes resist "division by any number other than zero and one". She means, of course, that a prime number resists division by any number other than itself and one. Every integer can count on two divisors: itself and one. All resist division by zero.

If we do not exclude unity and the number itself when summing up divisors, the 'abundant' numbers, whose divisors' sum is greater than themselves (for example, the number 18 referred to in the review), really would be abundant - and would include all numbers higher than one. Meanwhile, 'deficient' numbers such as the number 14, for which the divisors' sum is less, would be non-existent.

D. Speijer Academic Medical Centre, University of Amsterdam, Medical Biochemistry, Meibergdreef 15, 1105 AZ Amsterdam, the Netherlands e-mail:d.speijer@amc.uva.nl

Contributions to Correspondence may be submitted to

correspondence@nature.com They should be no longer than about 300 words, and ideally shorter, with no more than three references and three authors (for details, see http:// tinyurl.com/373jsv). Published contributions are edited. Science publishing issues of interest to authors are regularly featured at Nautilus (http:// blogs.nature.com/nautilus), where we welcome comments and debate. 